\title{
A versatile software-hardware system for environmental data acquisition and transmission
}

\author{
G. Zappalà \\ CNR Institute for Marine Coastal Environment Section of Messina, Italy
}

\begin{abstract}
In recent years increasing importance has been given to knowledge of the marine environment, either to help detect and understand global climate change phenomena, or to protect and preserve those coastal areas where multiple interests converge (linked to tourism, recreational or productive activities) and that suffer greater impact from anthropogenic activities; this has in turn stimulated the start of research programs devoted to the monitoring and surveillance of these particular zones, coupling the needs for knowledge, sustainable development and the exploitation of natural resources. Modern instruments rely on an electronic heart; an integrated hardware-software system developed in Messina is presented here, which is used in various versions to control data acquisition and transmission on buoys or on ship-based instrumentation. The system was originally conceived to implement a PC-like architecture; basically, it comprises a Pentium family CPU, a variable number of RS-232 ports to connect measuring instruments and communication devices, an analog to digital converter, power outputs to drive the actuators and switch on and off the measuring systems, a satellite and/or cellular phone modem and GPS; the mass storage is supplied by Disk on Chip (DOC) devices. The software enables one to fully control the system and the connected instruments both in local and remote mode using a special set of macro commands. A "sequence manager" can be activated to run pre-programmed macro-command sequences. The macro-commands enable one to manage the data acquisition and transmission, the mission programming, the system hardware and the measuring instruments. The whole system can be connected to another computer (local laptop or remote desktop) using terminal software; however, to fully and easily use its capabilities, a remote control program has been written. Thanks to the hardware-software architecture, it is easy to upgrade the system to more powerful processors without the need to completely rewrite the software.

Keywords: environmental monitoring, data acquisition and transmission.
\end{abstract}




\section{Introduction}

There is an increasing need to have data available in real time or near real time in order to activate proper measures in emergency situations. Cabled or wireless data transmission can be used. The first allows the transmission of a higher amount of data only in coastal sites, while the second gives a bigger flexibility in terms of application to different environments; moreover, using mobile (either terrestrial or satellite) phone services it is possible to allocate the data centre in the most convenient place, without any need of proximity to the sea.

To obtain a good synopticity of observations both in spatial and temporal domains, it is necessary to complement traditional ship observations with measurements from fixed stations (buoys moored in sites chosen to be representative of wider areas, or to constitute a sentinel against the arrival of pollutants), satellite observations, use of ships of opportunity and of newly developed instruments, like the gliders, or towed sliding devices, like the SAVE.

\section{Software-hardware interaction: design goals}

Several different (and somehow contrasting) needs must be faced in the system design:

- The CPU must offer high elaboration speed and low power consumption - really, power consumption vs. speed is a compromise, sometimes managed using sleep (halt) states;

- The software must be portable among different hardware platforms this means it should be written in a high-level language, but high-level languages (either interpreted or compiled) are not as efficient as lowlevel ones, so requiring higher elaboration speed (and more memory, which increases power consumption);

- The software must be very efficient - this means it must be strictly tailored on the hardware, but this assumption contrasts with former one;

- Mission programming (i.e. setting of kind and frequency of measurements) must be performed "on the fly", without recoding the managing software; this can be obtained using sequence files of macrocommands;

- New instruments must be added to the system easily and quickly.

\section{The firmware}

The software architecture was designed to be as modular as possible; it is based on three main modules, the "event machine", the "sequence manager" and the "parser", a number of "device" and "instrument" modules to fit the installed instruments and the data communication hardware, some auxiliary functions modules, written in various high and low level languages to run in ROMDOS. 


\subsection{The event machine}

As shown in Fig. 1, the event machine runs in an endless loop, waiting for one of the following events:

- arrival of a character from the communication device

- arrival of a character from the keyboard (during maintenance)

- occurrence of a timed event

- occurrence of a "position" event

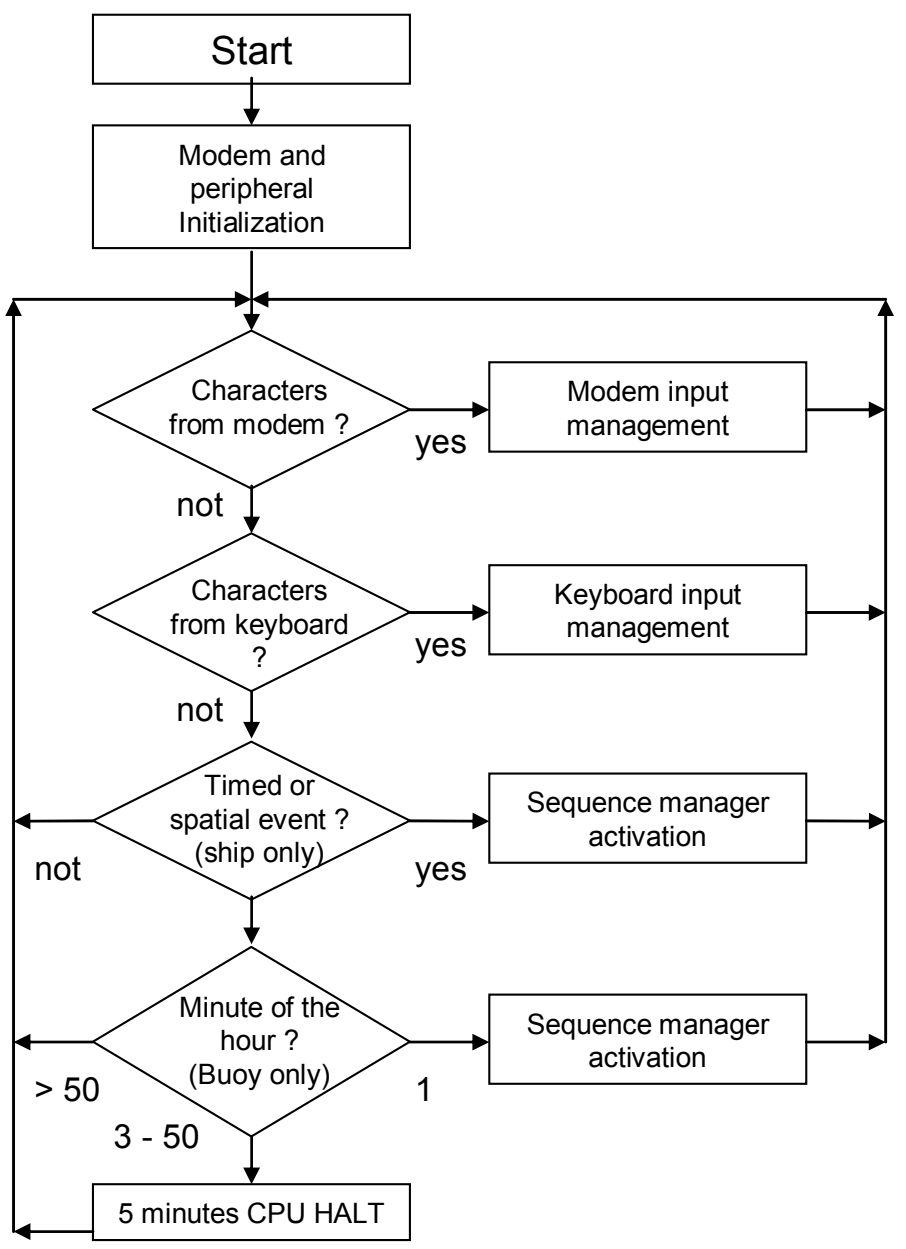

Figure 1: The event machine activity. 


\subsection{The modem input manager}

As shown in Fig. 2, when a character arrives from the modem, it activates a routine scanning the input string looking for the " $Z$ " character, which is recognised as the start of the remote command sequence; following characters up to the "LF" are then considered the command and sent to the parser to be interpreted.

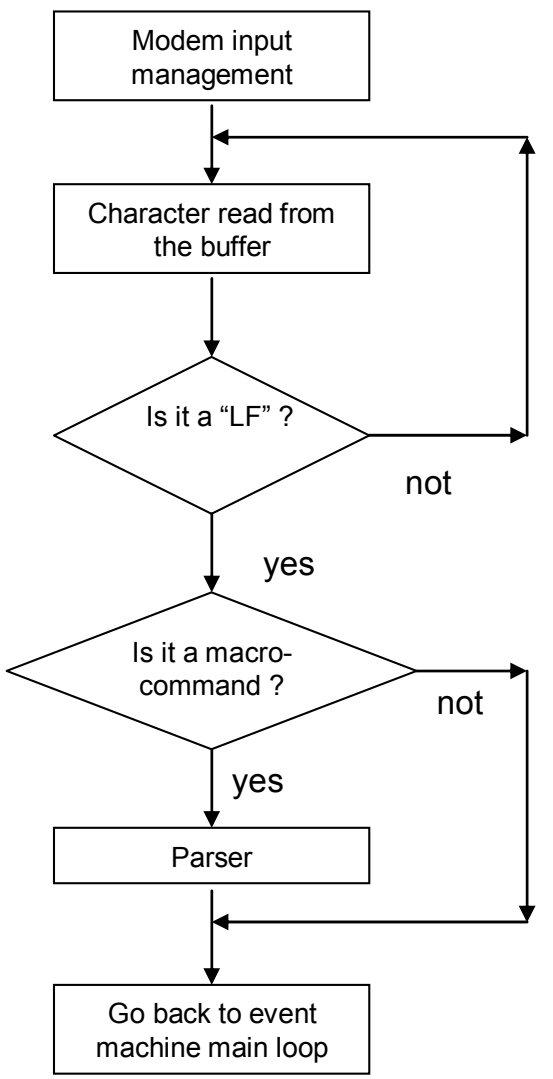

Figure 2: $\quad$ The modem input manager activity.

\subsection{The keyboard input manager}

The keyboard input manager, whose activity is shown in Fig. 3, allows one to locally interact with the data acquisition system during setup and test phases.

When a character arrives from the keyboard it is compared against the list of available commands and, if recognised, it is then executed. 
From this level, pressing ALT+"a key" it is possible to activate several utilities and sub-menus, made available according to the number and kind of measuring instruments fitted in the system

Main keyboard commands are:

- F1 to show the list of available commands

- $\quad \mathrm{ALT}+\mathrm{C}$ to issue local commands

- $\quad \mathrm{ALT}+\mathrm{D}$ to run a DOS shell

- $\quad \mathrm{ALT}+\mathrm{Q}$ to quit

- $\quad \mathrm{ALT}+\mathrm{R}$ to run a macro-command sequence

- $\quad \mathrm{ALT}+\mathrm{S}$ to run the modem SMS and e-mail management menu

- $\mathrm{ALT}+\mathrm{T}$ to activate the terminal utility

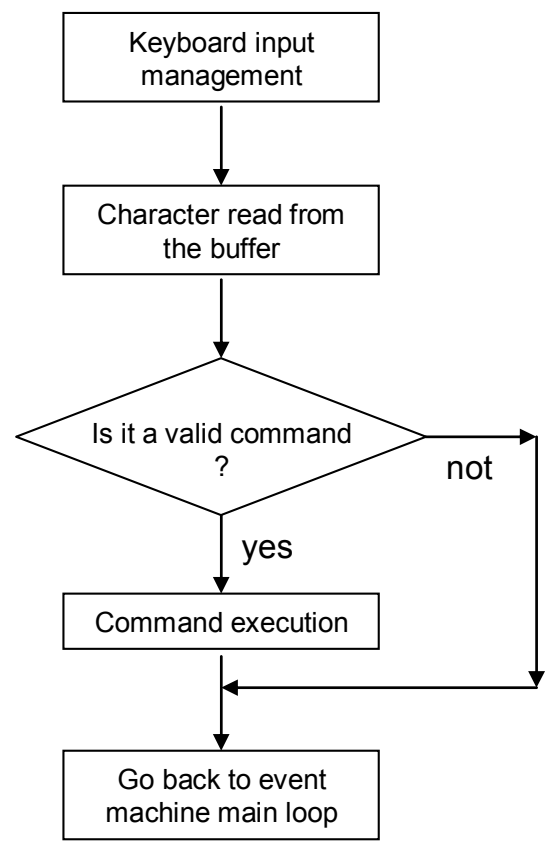

Figure 3: The keyboard input manager activity.

\subsection{The sequence manager}

The sequence manager is activated when an event occurs; according to the type of event, it opens the proper sequence file containing the macrocommands for that event, reads it line by line, sending each line to the "parser" to be interpreted and executed.

\subsection{The parser}

The "parser" receives in input a string supposed to contain a valid macrocommand, which, if found and recognised, is executed. 
The syntax of the commands is very easy: every macro command begins with the letter $\mathrm{Z}$, followed by a letter identifying the command and by the variable parameters (if any).

The macro-commands (that can be combined into sequences using a simple text editor) enable to fully control the system, the connected instruments, and the data transmission both in local and remote mode.

Conditional branch commands are also available; this feature can be very useful in case of partial operativity of the system due, for instance, to low battery level or failure of some instruments.

\subsection{The "device" modules}

These modules are written to fit the peculiarities of the computer hardware in assembly language and are installed as Interrupt Service Routines to be quickly and easily called.

\subsection{The "instrument" modules}

These modules are written to interface the computer with various measuring instruments, taking into account their peculiarities.

To obtain the maximum flexibility, parameters can be passed to the modules to specify the instrument address and the command to be performed.

The full set of commands (not supported by all instruments) includes:

- Instrument reset

- Instrument test

- Measurement performing and storing

Usually these modules don't need high elaboration speed, so they are written in compiled Basic or $\mathrm{C}$

\subsection{The data transmission routines}

The system can receive remote commands via modem, either in real time or as SMS (in this case a delay is possible).

It is possible to choose among different data transmission systems, using either terrestrial or satellite modems.

The first method uses a service offered by some telecom providers enabling to send e-mails encoded in an SMS; this solution is usually quite expensive and it should be used only where it is impossible to obtain an Internet connection

The second method simply connects the measuring station to Internet using a tcp-ip protocol, so allowing one to directly send e-mails.

The data path was designed to be fault tolerant:

- A copy of collected data is locally stored in the measuring station;

- A copy of the sent e-mail is also locally stored in the measuring station;

- In case of failure of the receiving mail server, the sending server (managed by the telecom company) will retry the delivery for some time, so allowing to repair the defective server without loss of messages; 
- All the mail messages are numbered, so enabling to detect undelivered ones and ask the remote station for retransmission;

- As soon as they are received, the mail messages are immediately assimilated into the data bank, and a copy remains for some time in the mail server.

- $\quad$ Periodic back-up operations are performed on the data base.

The command-data flow is described in Fig. 4.

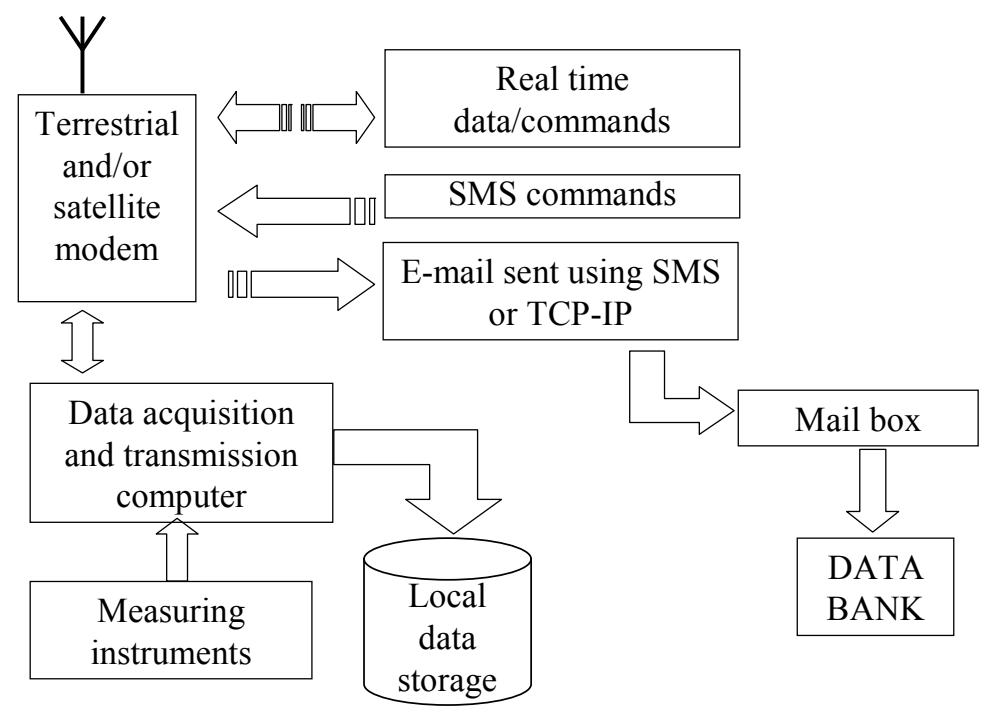

Figure 4: The command-data flow.

\section{The hardware}

The data acquisition and transmission system was originally conceived to implement a PC-like architecture running a ROMDOS (a ROM based operating system similar to MS-DOS) environment ; this choice was due to the availability of both industry-grade boards and of native software development tools in high and low level languages (assemblers, Basic and C compilers, debuggers...).

The boards comply with IEEE 696 (PC104) standard, which defines the dimensional and electrical characteristics of these devices.

Basically, the standard defines a size $(90 \times 96 \mathrm{~mm})$ and a connector layout (replicating the standard IDE signals found in the traditional PC-AT).

Boards can be stacked one above the other, to add new peripherals and functions to the system.

Usually, the board set could comprise:

- A CPU board including:

○ RAM and ROM (usually rewritable) memory

○ Disk-on-chip or Disk-on-module memory hosting

○ keyboard and video interface 
○ soft-hard disk interface

- serial port interface (up to 4)

- parallel port interface

o other interfaces (USB, audio, mouse...) not used in this application

- $\quad$ Serial ports expansion board (usually 8 ports/board)

- Analog to digital converter (up to 16 single-ended input channels) with 12 bit (for system diagnostic) or 16 bit (for measurement purposes) resolution.

- Remote communication device board (GSM-GPRS modem) often integrated with a GPS module; sometimes this board is substituted with devices connected to serial ports obtaining better performances (higher data transmission speed, satellite communication, tcp-ip integrated stack...)

- $\quad$ Digital I/O board

- Relay board to switch on and off the connected instruments, or semiconductor power interfaces driven by the digital $\mathrm{I} / \mathrm{O}$ board or by the parallel printer interface usually included in the CPU board.

According to the measuring needs and to power supply availability, the hardware can be fully or only partly implemented.

\section{Utility software}

Softwares were developed in Visual Basic to run in Windows environment to help manage the systems.

\subsection{The control terminal}

This program integrates a Terminal program with some utilities: an "application sequence generator", a "launch scheduling module", an "HEX file generator", a "file upload manager" and a "remote file manager module".

From the main terminal window it is possible to customize and use the terminal program or to activate the specific utilities.

\subsubsection{The application sequence generator}

The "application sequence generator" is a menu-driven utility that generates the "sequence" files containing the macro commands for mission programming.

\subsubsection{The launch scheduling module}

This module was developed to enable setting probe release parameters in operation from ships of opportunity.

\subsubsection{The HEX file generator}

It is possible to transfer files to the data acquisition and transmission system coding them in a specifically designed format, somehow similar to an ASCII coded hexadecimal dump, with checksum and transmission order information. 
Although not very fast (it increases the amount of data to be transmitted), this format is a reliable and safe way to encode small amounts of data (e.g. the "sequence files" generated by the "application sequence generator").

\subsubsection{The file upload manager}

This utility was designed to perform automatic uploads of "HEX" files to the data acquisition and transmission systems in the buoys; it can work in a "manual", "automatic", or "blind" mode.

The file transfer happens one line at a time, with the first line (numbered 0000) containing the file name and the last line (numbered 9999) signalling the end of file.

In "blind" mode, the lines are sequentially sent, at timed intervals, without waiting for any feedback; in "manual" mode, the user will wait for a feedback from the remote computer, then will choose to press the ENTER key to send next line, or BACKSPACE to resend the most recently transmitted; in "automatic" mode, every need is managed by the program.

It is possible to start (or resume) the file transmission at any line number.

\subsubsection{The remote file manager module}

This module gives remote control of the measuring station file system offering DIR, COPY, DELETE and RENAME facilities

\section{Some applications}

Several versions of the data acquisition and transmission system were built; the first one was used in a network of coastal monitoring buoys; a second one equips an automatic multiple launcher for expendable probes; microcontroller-based version were also designed to equip small instruments.
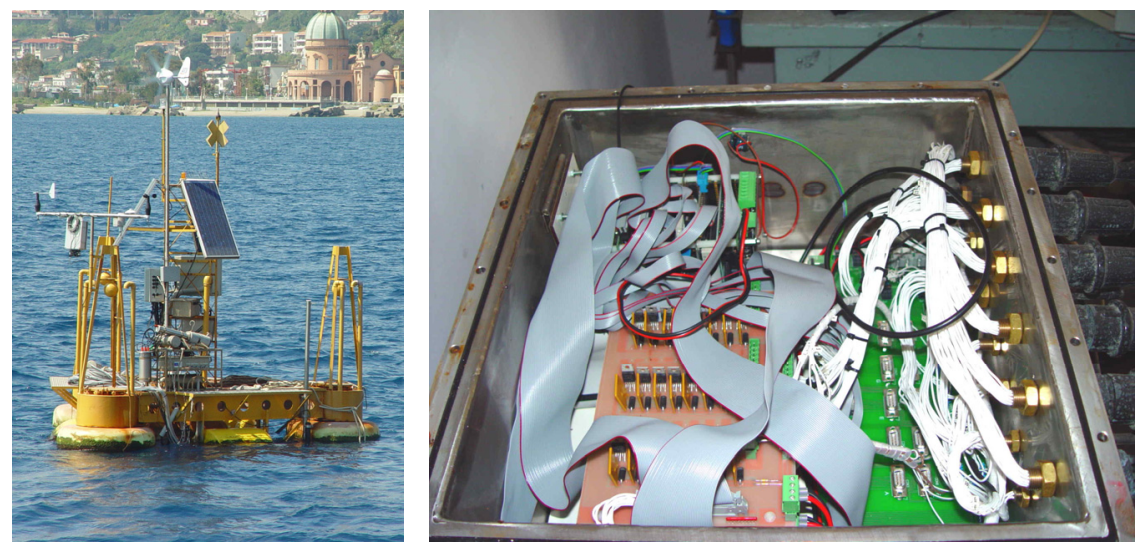

Figure 5: A buoy near Messina (left) and a close-up view of the control electronics (right). 


\subsection{The "buoy" version}

This release was used at the beginning of the century to equip a network of coastal monitoring buoys in the South of Italy, one of which is shown in Fig. 5.

These buoys, described by Zappalà et al. [1] were equipped with:

- a meteo station measuring air temperature, wind direction and speed, pressure, solar radiation

- a system for pumping water samples from 5 depths to measure water Temperature, Conductivity, Dissolved Oxygen, Turbidity, Fluorescence

- 5 in situ temperature probes at the same sampling depths

- an experimental colorimetric Nutrient Probe Analyzer sequentially measuring in few minutes ammonia, nitrate, nitrite and orthophosphate

- a water sampler for microbiological laboratory analysis, able to collect, fix with formalin and store up to eight $250 \mathrm{ml}$ samples

- $\quad$ an Acoustic Doppler Current

\subsection{The "launcher" version}

A main goal of a Ship of Opportunity Programme (SOOP) is the provision of sea temperature profiles in (near) real time. The use of commercial ships and expandable probes allows the reduction of costs, in comparison with research ship cruises. A major cost effectiveness is achieved using automated systems, requiring minimum personnel effort. An autonomous multiple launcher was developed in the framework of the Mediterranean Forecasting System - Toward Environmental Prediction Project (MFSTEP), able to automatically collect eight temperature profiles, using a software-programmable sampling strategy. The device, shown in Fig. 6, is described by Zappalà et al. [2, 3]

In the "launcher" version the program monitors the position of the hosting ship, comparing GPS data against the programmable set of launch points-times.
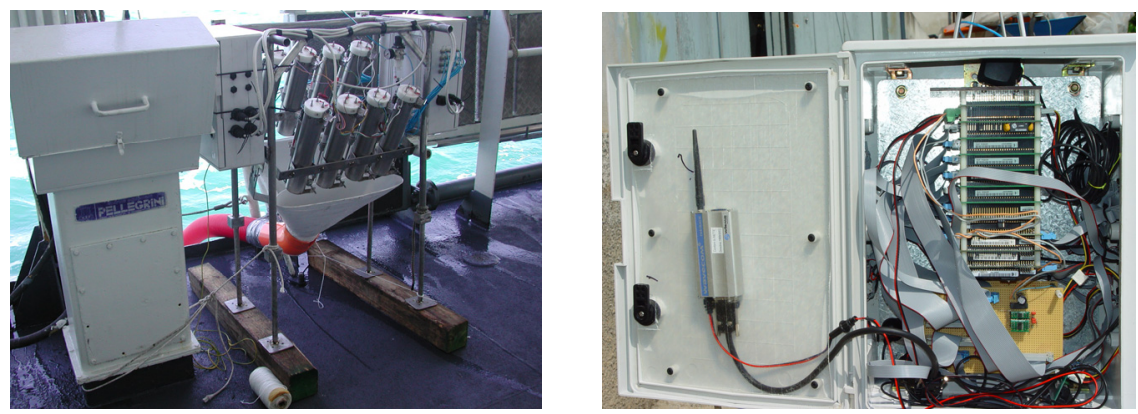

Figure 6: The launcher on the deck of the Magnaghi ship (left) and its control electronics (right). 


\section{Discussion}

The need for advanced systems to survey water quality and meteorological parameters, both at medium and long term scales, stimulated in recent years the development of different kinds of coastal and offshore buoys and platforms, like those described, among the others, by Grisard [4], Griffiths et al. [5], Paul [6], Seim et al. [7], Pinardi et al. [8].

The systems here described constitute a further improvement and application of the know-how acquired in past programmes, described in Crisafi et al. [9], Zappalà et al. [10], Zappalà [11], Zappalà et al. [12], Zappalà [13] and were funded in the framework of Italian ("SAM" Sistemi Avanzati di Monitoraggio Advanced Monitoring Systems) and European ("MFSTEP" Mediterranean Forecasting System Towards Environmental Predition) programmes.

The observing systems can perform meteorological observations and measurements of physical, chemical and physico-chemical parameters characterizing sea water state and quality, current speed and direction; the measuring devices range from "static" sensors (e.g. Pt100 for temperature) to colorimetric analyzers for nutrients; a water sampler, taking samples for further laboratory determinations, may also be included in the systems to complete the series of measurable parameters.

Water measurements can be carried out in situ at fixed depths, on samples pumped from various depths into a measurement chamber, using expendable profiling probes, or profiling instruments, like the SAVE described by Zappalà et al. [14], that adopted a microcontroller reduced version of the "launcher" electronics, with a software subset.

New releases of the software and of the sequences are uploadable to the system without suspending its normal activity. The macro-commands enable to manage the data acquisition and transmission, the mission programming, the system hardware and the measuring instruments.

Thanks to the hardware-software architecture, it is easy to upgrade the system to more powerful processors without the need to completely rewrite the software, which can be easily coded using standard development packages.

\section{References}

[1] Zappalà, G., Caruso, G., \& Crisafi, E., The "SAM" integrated system for coastal monitoring. Proc. of the 4th Int. Conf. On Environmental Problems in Coastal Regions, Coastal Environment IV, ed. C.A. Brebbia, WIT Press: Southampton, pp. 341-350, 2002.

[2] Zappalà, G., Manzella G., An automatic multiple launcher for expendable probes. Proc. of the Fourth International Conference on EuroGOOS. Operational Oceanography: Present and Future, eds. H. Dahlin, N.C. Flemming, P. Marchand \& S. E. Petersson, European Commission Publication Office, pp. 188-191, 2006. 
[3] Zappalà, G., Reseghetti, F., Manzella, G., Development of an automatic multiple launcher for expendable probes. Ocean Sciences, 3, pp. 173-178, 2007 Online. www.ocean-sci.net/3/173/2007/

[4] Grisard, K., Eight years experience with the Elbe Estuary environmental survey net. Proc. of OES-IEEE OCEANS '94 Conference, I, pp. 38-43, 1994.

[5] Griffiths, G., Davis, R., Eriksen, C., Frye, D., Marchand, P., Dickey, T., Towards new platform technology for sustained observations. Proc. of OceanObs 99. Online www.bom.gov.au/OceanObs99/Papers/Griffiths.pdf

[6] Paul, W., Buoy Technology. Marine Technology Society Journal, 35 (2), pp. 54-57, 2001.

[7] Seim, H., Werner, F., Nelson, J., Jahnke, R., Mooers, C., Shay, L., Weisberg, R., Luther, M., Proc. of SEA-COOS: Southeast Atlantic Coastal Ocean Observing System. MTS-IEEE OCEANS 2002 Conference, I, pp. 547-555, 2002.

[8] Pinardi, N., Allen, I., Demirov, E., De Mey, P., Korres, G., Laskaratos, A., Le Traon, P.Y., Maillard, C., Manzella, G., Tziavos, C., The Mediterranean Ocean Forecasting System: first phase of implementation (1998-2001). Annales Geophysicae, 21, pp. 3-20, 2003.

[9] Crisafi, E., Azzaro, F., Zappalà, G., Magazzù, G., Integrated automatic systems for oceanographic research: some applications. Proc. of OES-IEEE OCEANS '94 Conference, I, pp. 455-460, 1994.

[10] Zappalà, G., Alberotanza, L., Crisafi, E., Assessment of environmental conditions using automatic monitoring systems. Proc. of MTS-IEEE OCEANS '99 Conference, II, pp. 796-800, 1999.

[11] Zappalà, G., Advanced technologies: equipments for environmental monitoring in coastal areas. Science-technology synergy for research in marine environment - Developments in Marine Technology, eds. L. Beranzoli, P. Favali, and G. Smriglio, Elsevier: Amsterdam, pp. 261-268, 2002.

[12] Zappalà, G., Caruso, G., Crisafi, E., Design and use of advanced technology devices for sea water monitoring. Operational Oceanography. Implementation at the European and regional Scales, eds. N.C. Flemming, S. Vallerga, N. Pinardi, H.W.A. Behrens, G. Manzella, D. Prandle, and J.H. Stel, Elsevier: Amsterdam, Oceanography Series, 66, 2002.

[13] Zappalà, G., A software set for environment monitoring networks. Proc. of the Int. Conf. On Development and Application of Computer Techniques to Environmental Studies X. Envirosoft 2004, eds. G. Latini, G. Passerini, \& C. A. Brebbia, WIT Press, Southampton, pp. 3-12, 2004.

[14] Zappalà, G., Marcelli, M., Piermattei, V., Development of a sliding device for extended measurements in coastal waters. WIT Transactions on Ecology and the Environment, eds. D. Prats Rico, C.A. Brebbia, Y. Villacampa Esteve, WIT Press, Southampton, pp 187-196, 2008. 